\title{
Pharmacokinetics of iron isomaltoside 1000 in patients with inflammatory bowel disease
}

This article was published in the following Dove Press journal:

Drug Design, Development and Therapy

6 March 2012

Number of times this article has been viewed

\section{Kim Nordfjeld \\ Hans Andreasen \\ Lars L Thomsen}

Pharmacosmos A/S, Holbaek, Denmark
Correspondence: Lars Lykke Thomsen Pharmacosmos A/S, Clinical R\&D, Roervangsvej 30, Holbaek, DK-4300, Denmark

Tel +45 59485935

$\mathrm{Fax}+4559485960$

Email Ilt@pharmacosmos.com
Background: Iron isomaltoside 1000 is a novel injectable iron compound which offers potential advantages in the treatment of subjects with iron-deficiency anemia. We studied the pharmacokinetics (PK) of this novel compound in subjects with mild-to-moderate inflammatory bowel disease (IBD).

Methods: This open-label, crossover, single-center trial was conducted in 12 subjects with IBD who were allocated to one of the two single intravenous (IV) bolus sequences of iron isomaltoside 1000: $100 \mathrm{mg}$ followed by $200 \mathrm{mg}$, or vice-versa. PK variables were analyzed according to a single-compartment model.

Results: The concentration-versus-time relationship for isomaltoside-bound iron (IBI) and total iron (TI) showed first-order kinetics with small deviations from dose-linearity. The area under the concentration-time curve (AUC) values in $\mathrm{h} * \mu \mathrm{g} / \mathrm{mL}$ for IBI following $100 \mathrm{mg}$ and $200 \mathrm{mg}$ doses were 888 and 2141 respectively, and for TI following $100 \mathrm{mg}$ and $200 \mathrm{mg}$ doses, the AUC values were 1010 and 2319 respectively. The corresponding maximum serum concentration $\left(\mathrm{C}_{\max }\right)$ values in $\mu \mathrm{g} / \mathrm{mL}$ were 35.6 and 68.6 for IBI, and 37.3 and 71.1 for TI. The half-life $\left(\mathrm{T}_{1 / 2}\right)$ values for IBI and TI were between 20.8-23.5 hours. The apparent volume of distribution $\left(\mathrm{V}_{\mathrm{D}}\right)$ ranged from 3.0-3.5 L. Only approximately $1 \%$ of the doses administered were excreted in the urine. No serious adverse event (SAE) was reported. One subject was withdrawn after the $100 \mathrm{mg}$ dose due to abdominal pain and flushing.

Conclusion: At the administered doses, iron isomaltoside 1000 showed first-order PK, and did not raise safety concerns in patients with IBD. The PK parameters for IBI were close to those of TI.

Keywords: inflammatory bowel disease, iron deficiency anemia, iron treatment, iron isomaltoside, pharmacokinetics

\section{Introduction}

Iron deficiency anemia is estimated to affect approximately 1.6 billion people worldwide. ${ }^{1}$ It is the most common type of anemia associated with inflammatory bowel disease (IBD), which affects approximately $33 \%$ of sufferers, particularly in conjunction with acute exacerbation of the disease in which bleeding is common. Iron supplementation can generally be accomplished by the oral or intravenous (IV) routes; however, in IBD patients approximately $90 \%$ of the ingested iron is not absorbed, passes the sites of intestinal inflammation, and induces local oxidative stress at sites of active inflammation. Therefore, the IV route is preferable for iron supplementation in IBD patients. $^{2}$

Iron isomaltoside 1000 (Monofer ${ }^{\circledR}$; Pharmacosmos A/S, Holbaek, Denmark) is a new chemical structure developed by complexing ferric hydroxide with 
isomaltoside 1000 . Isomaltoside 1000 is a chemical modification of isomaltooligosaccharides with a mean molecular weight of $1000 \mathrm{Da}$, consisting predominantly of 3-5 glucose units. In contrast to dextrans, isomaltoside 1000 is linear and unbranched, with a low immunological potential - hence, a test dose is unnecessary. Iron isomaltoside 1000 contains strongly-bound iron within an iron-isomaltoside matrix formulation, with little risk of free iron toxicity. ${ }^{3}$

The primary objective of this trial was to provide pharmacokinetic (PK) data for isomaltoside-bound iron (IBI), transferrin-bound iron (TBI), and total iron (TI) in subjects with an established diagnosis of IBD after IV bolus injection of iron isomaltoside 1000, including the potential contribution of urine excretion to the elimination of IBI from plasma. The secondary objective was to assess the tolerability and safety of iron isomaltoside 1000 in this patient population.

\section{Material and methods Ethics}

This study was conducted at a single center in Denmark (PhaseOneTrials A/S) in accordance with the Declaration of Helsinki and complied with International Conference on Harmonization Good Clinical Practice (GCP) and applicable regulatory requirements. Prior to commencement, the trial protocol and/or other relevant documents were approved by the Independent Ethics Committee. Before each subject was admitted to the trial, written informed consent was obtained from the subject according to Danish regulatory and legal requirements.

\section{Trial design, outcomes, and eligibility criteria}

This was an open-label, crossover, single center, PK trial of iron isomaltoside 1000 given as IV bolus doses of $100 \mathrm{mg}$ or $200 \mathrm{mg}$ to subjects with IBD.

Inclusion criteria were the following: mild-to-moderate IBD (colitis ulcerosa or Crohn's disease) for at least 3 months, aged $18-70$ years, $s$-ferritin $<800 \mu \mathrm{g} / \mathrm{L}$, transferrin saturation $<30 \%$, life expectancy beyond 12 months, hemoglobin $(\mathrm{Hb})$ levels from $8.9-15.3 \mathrm{~g} / \mathrm{dL}$ in male patients, and $\mathrm{Hb}$ levels from $8.9-13.7 \mathrm{~g} / \mathrm{dL}$ in female patients. Exclusion criteria were the following: patients with severe IBD or surgery within the last 8 weeks, noniron deficiency anemia, iron overload or hemochromatosis or hemosiderosis, previous hypersensitivity to iron dextran or monodisaccharide complex, history of multiple allergies, liver cirrhosis or hepatitis, acute or chronic infections, rheumatoid arthritis, pregnancy or breastfeeding, active bleeding, planned elective surgery during the study where significant blood loss was expected, and participation in any other clinical study within 3 months prior to screening.

The duration of the trial period for each individual subject was a maximum of 7 weeks and consisted of nine visits: Visit 1 (Day -14 to Day -3 , screening), Visit 2 (Day -1, randomization; Day 0, baseline and dosing), Visit 3 (24 hours postdose), Visit 4 (48 hours postdose), Visit 5 (72 hours postdose), followed by a washout period of 28 days, Visit 6 (Day -1 , rehospitalization and Day 0, baseline and dosing), Visit 7 (24 hours postdose), Visit 8 (48 hours postdose), and Visit 9 (72 hours postdose and treatment termination visit). Visit 9 was also to be carried out in withdrawn subjects who had received at least one dose of iron isomaltoside 1000. Blood samples for PK assessments were drawn at the following time points: $-30,0,5,10,15,30$, and 45 minutes, and at $1,1.5,2,4,8,12,24,48$, and 72 hours.

Iron isomaltoside 1000 was administered twice to each subject as a single IV bolus dose, with a minimum dose interval of at least 4 weeks. The first six subjects were allocated to group $1(100 \mathrm{mg} / 200 \mathrm{mg})$, and the next six subjects were allocated to group 2 (200 mg/100 mg). Iron isomaltoside 1000 was administered at an injection rate of $50 \mathrm{mg}$ iron/min for both doses. For safety reasons, dosing of individual subjects was performed with 30-minute intervals.

TI and TBI were measured in plasma and urine, and IBI was estimated as the difference between the two. The PK parameters were estimated according to a single-compartment model, and included maximum serum concentration $\left(\mathrm{C}_{\max }\right)$; time to $\mathrm{C}_{\max }\left(\mathrm{T}_{\max }\right)$, calculated serum concentration at time 0 $\left(\mathrm{C}_{0}\right)$ obtained by back-extrapolation to time 0 of the log-linear regression at the $12,24,48$, and 72 hour sample points, area under the serum concentration-time curve from injection to last measurable data point $\left(\mathrm{AUC}_{0-\text { end }}\right)$, area under the serum concentration-time curve from injection to infinity $\left(\mathrm{AUC}_{\mathrm{inf}}\right)$; the elimination constant $\left(\mathrm{K}_{\mathrm{e}}\right)$ derived from each dosing episode profile by log-linear regression at the $12,24,48$, and 72 hour sample point, $\mathrm{T}_{1 / 2}$ derived from $\mathrm{K}_{\mathrm{e}}$, and apparent $\mathrm{V}_{\mathrm{D}}$ derived from $\mathrm{C}_{0}$. Urine was sampled accumulatively during four time intervals following each dosing event: $0-8,8-24$, 24-48, and 48-72 hours.

The safety parameters included laboratory tests (hematology, biochemistry, and urine analyses), physical examination, vital signs (blood pressure, heart rate, and body temperature), electrocardiogram (ECG), incidence and severity of adverse events (AEs), and adverse drug reactions (ADRs). 


\section{Analytical methods}

IBI in human serum was analyzed by Unilabs A/S (Copenhagen, Denmark) (a GCP- and ISO17025-accredited laboratory), by means of differentiation method. The TI content was determined by Graphite Furnace Atomic Absorption Spectrometry (GFAAS) system with Zeeman background correction delivered by Varian (now Agilent Technologies, Santa Clara, CA). The content of TBI was determined by photometry on an automated Advia 1650 Chemistry System delivered by Bayer HealthCare (now Siemens Healthcare Diagnostics, Munich, Germany). Subtracting the Advia result from the GFAAS result yielded the content of IBI, assuming that no free iron was present and that amounts of ferritin were negligible, so that the only iron forms present in plasma were TI, TBI, and IBI. The interassay precision (coefficient of variation) of the GFAAS and Advia quality control samples ranged between $7.6 \%-10.2 \%$ for the GFAAS analysis, and between 1.0\%-1.1\% for the Advia analysis. The mean inaccuracy ranged between $-1.1 \%-6.9 \%$ for the GFAAS analysis and between $-1.7 \%$ and $-3.2 \%$ for the Advia method. The GFAAS method was used to measure the total quantity of iron in serum samples after acid digestion $\left(65 \% \mathrm{HNO}_{3}\right)$ at $115^{\circ} \mathrm{C}$ followed by the addition of Triton-X-100 to obtain a tenfold dilution. A linear calibration curve was achieved by the principles of standard addition by programming the GFAAS instrument to automatically add different concentrations of iron standard to human serum containing $43.57 \mu \mathrm{mol} / \mathrm{L}$. The added iron standard was prepared by spiking water with iron isomaltoside 1000 to a concentration of $69.56 \mu \mathrm{mol} / \mathrm{L}$, followed by dilution to the added concentration.

The concentration of IBI in urine was also analyzed by means of a differentiation method based on the same laboratory methods as for serum iron determination: GFAAS for TI, and Advia for TBI. The quality of the method for determination of IBI was satisfactory. The interassay precision (coefficient of variation) of the GFAAS and Advia quality control samples ranged between $1.1 \%-6.9 \%$ for the GFAAS analysis, and between $0.2 \%-0.4 \%$ for the Advia analysis. The mean inaccuracy ranged between $-1.8 \%$ and $14.9 \%$ for the GFAAS analysis and between $1.4 \%-4.1 \%$ for the Advia method.

GFAAS analytical method was used to measure the total quantity of iron in urine samples after dilution and addition of Triton-X-100. The instrument is linear-calibrated, using Titrisol-spiked calibrators produced by Unilabs A/S. The calibration curve ranged from $0.0-10.1 \mu \mathrm{mol} / \mathrm{L}$. For determination of TBI in urine by ADVIA method, $\mathrm{Fe}^{3+}$ was first separated from transferrin under acidic conditions, then reduced to $\mathrm{Fe}^{2+}$ with ascorbic acid and finally combined with Ferrozine, to give a chromogenic complex which absorbs at $571 / 658 \mathrm{~nm}$.

\section{Statistical methods}

The crossover design - with a washout period in between the two exposures to different doses of iron isomaltoside 1000 - created a pairing of results that was utilized during the analyses. It was not relevant to adjust for multiplicity. A formal sample size calculation was not performed. However, based on data on $s$-iron concentrations from a previous trial (data on file) the coefficient of variation (CV) of the mean $\mathrm{C}_{\max }$ was expected to be in the range of 5\%-7\% in 12 subjects. It was assessed that this was a sufficient precision for the PK endpoints. A sample size of 12 subjects was therefore decided.

Primary PK endpoints, $\mathrm{AUC}_{0-\mathrm{end}}$ and $\mathrm{C}_{\max }$, were logtransformed and analyzed in a mixed linear normal model, with treatment and visit as fixed effects and subject as random effect. The subject factor was included to implement the crossover feature of the design.

All primary and secondary endpoints are presented with summary statistics. Descriptive statistics for continuous variables were presented with $N$, mean, standard deviation (SD), geometric mean, and $\mathrm{CV}$, where $N$ denotes the number of subjects contributing with nonmissing data. For discrete variables, descriptive statistics was presented with $N$ and percentage of the number of subjects contributing, with nonmissing data in the various categories of the variable.

\section{Adverse events}

AEs were recorded at all postbaseline visits, and classified according to Medical Dictionary for Regulatory Activities (MedDRA) system, version 10.1. ${ }^{4}$

\section{Results}

\section{Patient disposition and demographics}

A total of 36 subjects were screened, of which 12 subjects with IBD defined by the Lennard-Jones criteria ${ }^{5}$ were included. All subjects were dosed with the two doses $(100 \mathrm{mg}$ and $200 \mathrm{mg}$ or $200 \mathrm{mg}$ and $100 \mathrm{mg}$ ), and completed the study except for one subject who only received a single dose of $100 \mathrm{mg}$ before being withdrawn due to an AE. One subject had slightly elevated $s$-creatinine at inclusion. Baseline demographic data are presented in Table 1. 
Table I Baseline characteristics

\begin{tabular}{|c|c|c|c|}
\hline & Treatment: $100 \mathrm{mg}+200 \mathrm{mg}$ & Treatment: $200 \mathrm{mg}+100 \mathrm{mg}$ & All subjects \\
\hline$N$ & 6 & 6 & 12 \\
\hline \multicolumn{4}{|l|}{ Age (years) } \\
\hline Mean (SD) & $49.3(13.7)$ & $29.5(5.8)$ & $39.4(14.4)$ \\
\hline \multicolumn{4}{|l|}{ Sex, $N(\%)$} \\
\hline Women & $3(50.0)$ & $4(66.7)$ & $7(58.3)$ \\
\hline Men & $3(50.0)$ & $2(33.3)$ & $5(4 I .7)$ \\
\hline \multicolumn{4}{|l|}{ Race, N (\%) } \\
\hline Caucasian & $6(100.0)$ & $6(100.0)$ & $12(100.0)$ \\
\hline \multicolumn{4}{|l|}{ Height (m) } \\
\hline Mean (SD) & $\mathrm{I} .74(0.1)$ & $\mathrm{I} .72(0.1)$ & $\mathrm{I} .73(0.1)$ \\
\hline \multicolumn{4}{|c|}{ Weight at baseline (kg) } \\
\hline Mean (SD) & $79.0(19.3)$ & $65.0(13.4)$ & $72.0(17.4)$ \\
\hline \multicolumn{4}{|c|}{ Body mass index at baseline $\left(\mathrm{kg} / \mathrm{m}^{2}\right)$} \\
\hline Mean (SD) & $25.9(6.1)$ & $21.8(1.8)$ & $23.8(4.8)$ \\
\hline \multicolumn{4}{|c|}{ Hemoglobin (mmol/L) } \\
\hline Mean (SD) & $8.1(0.4)$ & $8.0(0.9)$ & $8.1(0.7)$ \\
\hline \multicolumn{4}{|c|}{ S-ferritin $(\mu g / L)$} \\
\hline Mean (SD) & $73.2(53.1)$ & $65.8(48.2)$ & $69.8(48.5)$ \\
\hline \multicolumn{4}{|c|}{ Transferrin saturation (\%) } \\
\hline Mean (SD) & $18.6(6.7)$ & $12.7(7.8)$ & $15.4(7.6)$ \\
\hline \multicolumn{4}{|c|}{ C-reactive protein (mg/L) } \\
\hline Mean (SD) & $3.5(3.8)$ & $7.0(8.1)$ & $5.2(6.3)$ \\
\hline
\end{tabular}

\section{Pharmacokinetic results}

Serum-concentration versus time curves for IBI, TI, and TBI with log-transformed concentration values presented as mean \pm standard error (SE) are shown in Figure 1. The shape of the curves for IBI and TI is compatible with first-order PK.

The corresponding descriptive statistics (geometric means and $\mathrm{CV}$ ) are provided in Table 2. A more than twofold increase was observed in the mean $\mathrm{AUC}$ and $\mathrm{C}_{\text {max }}$ for the $200 \mathrm{mg}$ dose compared to the $100 \mathrm{mg}$ dose. The $\mathrm{K}_{\mathrm{e}}$ was slightly lower, and $\mathrm{T}_{1 / 2}$ was slightly longer for $200 \mathrm{mg}$ versus $100 \mathrm{mg}$ for IBI and TI (Table 2). This corresponds to a deviation from dose-linearity. The apparent $\mathrm{V}_{\mathrm{D}}$ ranged from 3.0-3.5 L.

The concentration-time curve shapes as well as the values of the mean AUC and $\mathrm{C}_{\max }$ for IBI were close to those of TI.

$S$-transferrin rose slowly, and achieved mean $\mathrm{C}_{\max }$ after approximately 5.5 hours, and then declined gradually. The ratio between AUC for TBI and TI was $16 \%$ for the $100 \mathrm{mg}$ dose and $10 \%$ for the $200 \mathrm{mg}$ dose.

Comparison of PK estimates between the two crossover periods did not reveal any period effect (data not shown).

Table 3 shows excretion of TI in urine. Overall, approximately $1 \%$ of the doses administered were excreted in the urine $(0.9 \%$ after the $100 \mathrm{mg}$ dose and $1.1 \%$ following the $200 \mathrm{mg}$ dose).

\section{Safety results}

No SAEs were reported. Nine subjects experienced a total of 43 nonserious AEs: 33 were mild, eight were moderate, and two were severe (Table 4). Thirty-one events were classified as related to trial drug (ie, ADRs), and 12 as unrelated. One subject was withdrawn from the trial due to an ADR after the first dose $(100 \mathrm{mg})$ of iron isomaltoside 1000 . Among the 11 ADRs experienced by this subject, two were graded as severe in intensity (abdominal pain and flushing). Despite this, the symptoms were not suggestive of an acute anaphylactic reaction; this subject was initially treated with antihistamine and glucocorticosteroid to prevent any progression of the acute reaction and/or a potential delayed allergic reaction. The subject was followed up and all ADR symptoms were resolved. No other subjects experienced severe ADRs. No clinically significant changes in laboratory parameters or vital signs were reported. Among all the AEs, three were local irritations and two of these were considered ADRs.

\section{Discussion}

Anemia is the most common systemic complication of IBD, and has considerable impact on quality of life. In a recentlypublished guideline on the diagnosis and management of anemia and iron deficiency in IBD, authors argued that IV iron appears to be more effective, better tolerated, and improves the quality of life to a greater extent than oral iron 

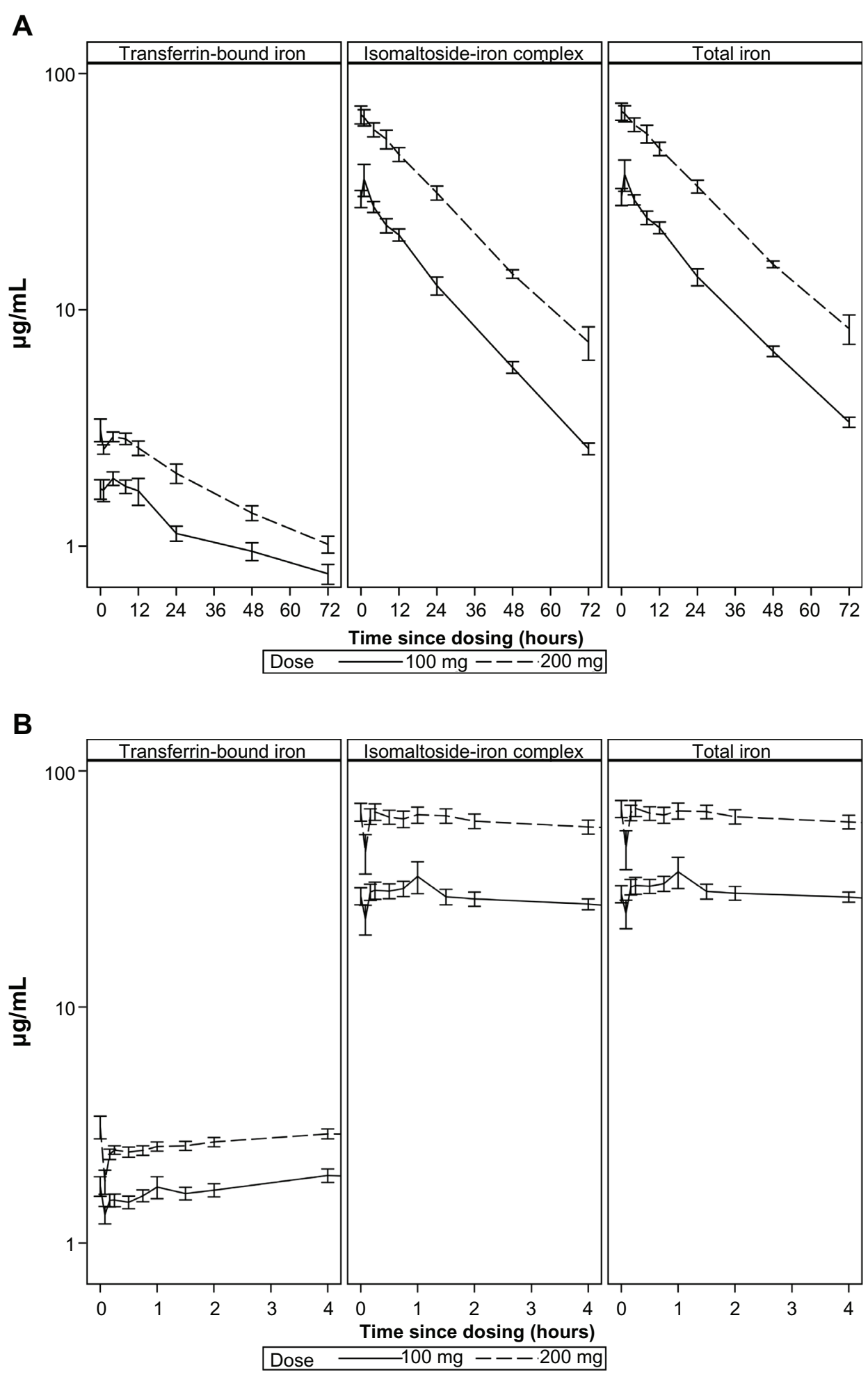

Figure I Iron concentration versus time in plasma (mean \pm SE) (log-scale). (A) 0-72 hours (reduced number of initial time points). (B) -0 to 4 hours.

supplements. ${ }^{2}$ The PK data obtained from this study can be considered valuable in this patient cohort, who may benefit from iron isomaltoside 1000 .

The concentrations of IBI in plasma and urine were derived from concentrations of TI and TBI, assuming that no free iron was present and that the amount of ferritin was negligible so that the only iron forms present in plasma were TI, TBI, and IBI. This so-called differentiation method was also used in the studies of PK of ferric gluconate,${ }^{6,7}$ while PK of ferumoxytol ${ }^{8,9}$ was based on direct 
Table 2 Geometric mean (CV in \%) for PK parameters of isomaltoside-bound iron, total iron, and transferrin-bound iron

\begin{tabular}{|c|c|c|c|c|c|c|}
\hline \multirow[t]{3}{*}{ Endpoint } & \multicolumn{2}{|c|}{ Isomaltoside-bound iron } & \multicolumn{2}{|c|}{ Total iron } & \multicolumn{2}{|c|}{ Transferrin-bound iron } \\
\hline & \multicolumn{2}{|c|}{ Treatment } & \multicolumn{2}{|c|}{ Treatment } & \multicolumn{2}{|c|}{ Treatment } \\
\hline & $100 \mathrm{mg}$ & $200 \mathrm{mg}$ & $100 \mathrm{mg}$ & $200 \mathrm{mg}$ & $100 \mathrm{mg}$ & $200 \mathrm{mg}$ \\
\hline $\mathrm{AUC}_{0 \text {-end }}(\mathrm{h} * \mu \mathrm{g} / \mathrm{mL})$ & $809(24)$ & $1885(20)$ & $894(2 I)$ & $2017(19)$ & $82.6(19)$ & $129(15)$ \\
\hline $\mathrm{AUC}_{0 \text {-inf }}(\mathrm{h} * \mu \mathrm{g} / \mathrm{mL})$ & $888(22)$ & $2|4|(23)$ & $1010(19)$ & $2319(21)$ & $163(67)$ & $228(5 \mathrm{I})$ \\
\hline$C_{\max }(\mu g / m L)$ & $35.6(39)$ & $68.6(26)$ & $37.3(38)$ & $71 . I(26)$ & $2.1(30)$ & $3.0(16)$ \\
\hline $\mathrm{T}_{\max }$ (minutes) & $37(109)$ & $27(104)$ & $38(15 \mathrm{I})$ & $28(I I 2)$ & $218(166)$ & $221(191)$ \\
\hline$C_{0}(\mu g / m L)$ & $28.3(32)$ & $64.5(29)$ & $28.9(32)$ & $66.7(28)$ & $1.7(36)$ & $2.9(37)$ \\
\hline $\mathrm{K}_{\mathrm{e}}(\mathrm{I} /$ hour $)$ & $0.033(12)$ & $0.031(24)$ & $0.030(15)$ & $0.029(23)$ & $0.011(85)$ & $0.013(87)$ \\
\hline $\mathrm{T}_{1 / 2}$ (hour) & $20.8(12)$ & $22.5(24)$ & $23.2(15)$ & $23.5(23)$ & $62.2(85)$ & $53.9(87)$ \\
\hline$V_{D}$ based on $C_{0}(L)$ & $3.5(32)$ & $3.1(29)$ & $3.5(32)$ & $3.0(28)$ & $60.6(36)$ & $68.3(37)$ \\
\hline
\end{tabular}

measurement of the drug-bound iron by MR spectrometry, and PK of iron-hydroxide sucrose complex were based on the measurement of TI. The PK parameters for IBI were close to that of TI, which implies that TI may be a good surrogate for IBI. Recent in vitro studies document that the tightly-bound iron isomaltoside 1000 matrix formulation contains a very low level of free iron. ${ }^{3,10}$ The fact that low-molecular-weight iron dextran had higher free iron in these experiments highlights the differences between these compounds. ${ }^{3,10}$

For both TI and IBI, the shape of the log-transformed concentration-versus-time curves were compatible with first order PK, which is consistent with the PK of iron-dextran for iron doses up to $500 \mathrm{mg},{ }^{11}$ and with ferumoxytol for iron doses up to $4 \mathrm{mg} / \mathrm{kg}$ after a single IV dose. ${ }^{8}$ This did not appear to be the case for ferric-gluconate ${ }^{6,7}$ nor for

Table 3 Total iron in urine $(\mu \mathrm{g} / \mathrm{mL})$

\begin{tabular}{|c|c|c|}
\hline \multirow[t]{2}{*}{ Time } & \multicolumn{2}{|l|}{ Treatment } \\
\hline & $100 \mathrm{mg}$ & $200 \mathrm{mg}$ \\
\hline \multicolumn{3}{|l|}{ Baseline $^{\mathrm{a}}$} \\
\hline No & 12 & II \\
\hline Mean (SD) & $0.212(0.0)$ & $0.212(0.0)$ \\
\hline \multicolumn{3}{|l|}{$0-8$ hours } \\
\hline No & II & II \\
\hline Mean (SD) & I.252 (0.586) & $2.191(0.654)$ \\
\hline \multicolumn{3}{|l|}{$8-24$ hours } \\
\hline No & 12 & 11 \\
\hline Mean (SD) & $0.252(0.050)$ & $0.453(0.154)$ \\
\hline \multicolumn{3}{|l|}{ 24-48 hours } \\
\hline No & II & II \\
\hline Mean (SD) & $0.213(0.003)$ & $0.218(0.019)$ \\
\hline \multicolumn{3}{|l|}{$48-72$ hours $^{\mathrm{a}}$} \\
\hline No & 12 & II \\
\hline Mean (SD) & $0.212(0.0)$ & $0.212(0.0)$ \\
\hline
\end{tabular}

Notes: a Concentrations below lower limit of quantification (LLOQ) were set to LLOQ. This occured for all measured urine iron concentrations at baseline and the 72 hour sample point. Hence, the means for these time points are identical and equal to $L L O Q$ with $S D=0$. iron-hydroxide sucrose complex ${ }^{12}$ both of which saw a fast initial drop during the first 4-6 hours, followed by a slower elimination rate.

For both IBI and TI, a more than twofold increase was observed in the mean AUC and $\mathrm{C}_{\max }$ for the $200 \mathrm{mg}$ dose, compared to the $100 \mathrm{mg}$ dose, which was a deviation from dose-linearity and correlates with PK of ferumoxytol, ${ }^{8}$ which likely represents the capacity-limited elimination from plasma to the reticuloendothelial system (RES) described previously. ${ }^{13}$ The $\mathrm{V}_{\mathrm{D}}$ based on apparent initial concentration ranged from 3.0-3.5 L. This corresponds roughly to the plasma volume (normally $40-50 \mathrm{~mL} / \mathrm{kg}$ ), and is comparable to the other IV iron preparations except ferric gluconate, for which a $V_{D}$ at steady-state reached $6.7 \mathrm{~L}$ in one study. ${ }^{6}$ This indicates that practically all IBI is contained in plasma before being eliminated by RES.

The PK analysis was done assuming a one-compartment model with first-order PK, the model also used for a single-dose study of ferumoxytol. ${ }^{8}$ Other authors used a two-compartment model for PK of iron-carbohydrate complex; for repeated-dose ferumoxyto ${ }^{9}$ and for ferric gluconate, ${ }^{7}$ however, both one- and two-compartment methods described the data accurately. For carbohydratebound iron, a one-compartment model makes sense from the physiological viewpoint. According to the literature, IV iron compounds are eliminated from plasma by the RES, which splits the compound into iron and carbohydrate. ${ }^{11,13}$ Once sequestered by RES, the complex cannot be restored in the circulation, thus the RES is not a "compartment" as there is no return of the complex from RES to plasma. Rather, RES should be considered as the elimination system for the complex.

However, two compartments may be considered for TI: plasma (central compartment) and RES (peripheral compartment) (Figure 2). RES is also an elimination pathway 
Table 4 Adverse events according to MedDRA preferred term and by severity

\begin{tabular}{|c|c|c|c|}
\hline & $\mathbf{N}^{\mathbf{a}}$ & $(\%)^{a}$ & $\mathbf{E}^{\mathbf{a}}$ \\
\hline Exposed subjects & 12 & & \\
\hline Total & 9 & 75 & 43 \\
\hline Mild & 9 & 75 & 33 \\
\hline Abdominal pain upper & 2 & 17 & 2 \\
\hline Abdominal tenderness & 1 & 8 & 1 \\
\hline Back pain & 1 & 8 & 1 \\
\hline Chest discomfort & I & 8 & I \\
\hline Constipation & 2 & 17 & 2 \\
\hline Cystitis & 1 & 8 & 1 \\
\hline Dizziness & 2 & 17 & 3 \\
\hline Dry mouth & 1 & 8 & 1 \\
\hline Dysgeusia & I & 8 & I \\
\hline Feeling cold & 1 & 8 & I \\
\hline Flushing & 1 & 8 & 1 \\
\hline Headache & 1 & 8 & 1 \\
\hline Hordeolum & 1 & 8 & 1 \\
\hline Injection site irritation & 2 & 17 & 2 \\
\hline Injection site pain & I & 8 & I \\
\hline Nasopharyngitis & 1 & 8 & 1 \\
\hline Nausea & 3 & 25 & 3 \\
\hline Sensory disturbance & 1 & 8 & 1 \\
\hline Rash & 1 & 8 & 2 \\
\hline Sensation of foreign body & I & 8 & 1 \\
\hline Tachycardia & 3 & 25 & 4 \\
\hline Moderate & 3 & 25 & 8 \\
\hline Abdominal discomfort & 1 & 8 & 1 \\
\hline Crohn's disease $^{\mathrm{b}}$ & 1 & 8 & 1 \\
\hline Dizziness & 1 & 8 & 1 \\
\hline Flushing & 1 & 8 & 2 \\
\hline Nausea & 2 & 17 & 2 \\
\hline Sensory disturbance & 1 & 8 & 1 \\
\hline Severe & 1 & 8 & 2 \\
\hline Abdominal pain upper & 1 & 8 & 1 \\
\hline Flushing & 1 & 8 & 1 \\
\hline
\end{tabular}

Notes: ${ }^{2} \mathrm{~N}$ : Number of subjects with event, $\%=$ percentage of exposed with event $\mathrm{E}=$ number of events; 'The lower level term was "Crohn's disease aggravated".

for TI, which is then either bound to intracellular storage proteins (eg, in the liver), or transported to bone marrow for hematopoiesis. Other elimination methods include urine excretion, and loss due to blood sampling. Although iron contained in storage proteins and iron incorporated into erythrocytes returns to plasma, this process is not part of the model since it is unlikely to occur before practically all iron has been eliminated from plasma, following a single administration of iron isomaltoside 1000. TBI is not considered a separate compartment for TI, since it is contained in the central compartment (plasma). Based on the ratio between AUCs for TBI and TI, $10 \%-16 \%$ of iron administered as IBI returns to plasma from the RES compartment, under the assumption that all measured TBI originates from the iron isomaltoside complex. Despite the theoretical presence of the RES compartment, the shape of the concentration-time curve for TI suggests that plasma and RES behave as a single compartment for the purposes of PK.

The elimination $\mathrm{T}_{1 / 2}$ for IBI and TI for the $100 \mathrm{mg}$ dose was 20.8 and 23.2 hours respectively, which is slightly shorter than $\mathrm{T}_{1 / 2}$ for iron dextran, which was approximately 30 hours, ${ }^{11}$ slightly longer than for ferumoxytol, which was approximately 16 hours for a $250 \mathrm{mg}$ dose $^{8}$, and significantly longer than the $\mathrm{T}_{1 / 2}$ for iron-sucrose complex, ${ }^{12}$ ferric carboxymaltose, and ferric gluconate. ${ }^{6,714} \mathrm{The}_{1 / 2}$ should be taken into account when selecting the dose frequency. The observed mean $\mathrm{T}_{\text {max }}$ values for IBI and TI ranged from 27-38 minutes. By comparison, $\mathrm{T}_{\max }$ values for TI after bolus injection of ferric carboxymaltose were 16 minutes after a bolus injection and 20, 60, and 72 minutes following a 15-minute infusion of 500,800 , and $1000 \mathrm{mg}$ respectively. ${ }^{15}$

Urine excretion was negligible (Table 3). The average amount excreted was $0.9 \%$ of the injected dose following administration of the $100 \mathrm{mg}$ dose (range: $0.6 \%-1.1 \%$ ) and following the $200 \mathrm{mg}$ dose the urine iron excretion was $1.1 \%$ of the dose administered (range: $0.7 \%-1.4 \%$ ). This indicates that renal elimination of iron associated with IV administration of iron isomaltoside 1000 is negligible, and this has two clinical implications: (1) that iron administered as iron isomaltoside 1000 is almost entirely confined to the organism and can be used for hematopoiesis; and (2) no impact of renal failure on the elimination of TI is expected. By comparison, the calculated proportion of ferric gluconate excreted in the urine was $2.4 \%$ and $2.3 \%$ after IV infusions of $62.5 \mathrm{mg}$ and $125 \mathrm{mg}$, respectively. ${ }^{6}$ For iron sucrose, the urine excretion of iron is more important and corresponds to $5 \%$ during the first 4 hours postdose. ${ }^{12}$

The iron loss due to plasma sampling was not taken into account. No allergic reactions were seen in the current trial. One subject experienced multiple AEs (11 ADRs reported on the $100 \mathrm{mg}$ dose) and was withdrawn after the first dose. Despite this, the symptoms were not suggestive of an acute anaphylactic reaction; the patient was initially treated with antihistamine and glucocorticosteroid to prevent any progress in the acute reaction and/or a potential delayed allergic reaction. The subject was followed up and all ADR symptoms were resolved.

There was no correlation between dosage and the number of ADRs or their severity. From the reported ADRs and their severity (excluding the withdrawn subject) it was not possible to correlate $\mathrm{ADRs}$ to $\mathrm{C}_{\max }$ or $\mathrm{AUC}$ from the different dosages. 


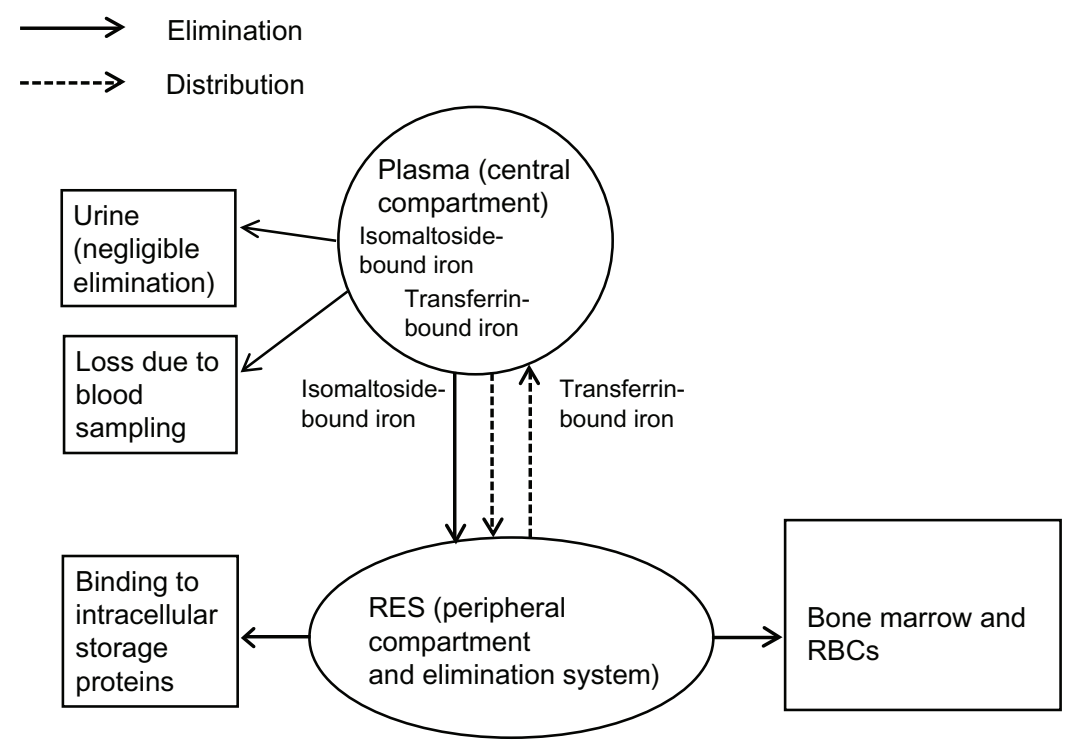

Figure 2 The theoretical two-compartment model for total iron.

Abbreviations: RBCs, red blood cells; RES, reticuloendothelial system.

There were too few reported ADRs, and from the review in the investigator's brochure there was no obvious relationship between either of the kinetic factors mentioned.

Overall, iron isomaltoside 1000 (100 mg and $200 \mathrm{mg}$ ) given as an IV injection not exceeding $50 \mathrm{mg}$ iron/minute showed, as expected, a first-order kinetic profile for both IBI and TI, and was also shown to be safe in the administered doses in this IBD-diagnosed patient group. The compound has been given at single doses from $100 \mathrm{mg}$ to as high as $1800 \mathrm{mg}$ to patients with either chronic kidney disease or chronic heart failure suffering from iron-deficiency anemia. ${ }^{16,17}$ Based upon the current study, TI can be used as surrogate for IBI in future PK studies with such high doses of iron isomaltoside 1000.

\section{Acknowledgments and disclosure}

KN, HA, and LLT are employed by the Sponsor, Pharmacosmos $\mathrm{A} / \mathrm{S}$. The sponsor was involved in the study design, collection, analysis and interpretation of data, in the writing of the manuscript, and in the decision to submit the manuscript for publication.

$\mathrm{KN}$ was involved in the design, project management during collection of data, data analyses, and preparation of the manuscript. HA was involved in the design, data analyses, and preparation of the manuscript. LLT was involved in the design, data analyses and preparation of the manuscript. All authors read and approved the final manuscript.

Acknowledgment to all contributors who did not meet the criteria for authorship: The CRO PhaseOneTrials A/S contributed to collection of data, Dr Ewa Lindestrøm provided medical writing assistance and gave scientific input during preparation of the manuscript, Jens K Slott Jensen MSc provided statistical support. The sponsor paid for this assistance.

\section{References}

1. de Benoist B, McLean E, Egli I, Cogswell M. Worldwide Prevalence of Anaemia 1993-2005: WHO Global Database on Anaemia. Available from http://whqlibdoc.who.int/publications/2008/9789241596657_eng. pdf. Accessed January 11, 2012.

2. Gasche C, Berstad A, Befrits R, et al. Guidelines on the diagnosis and management of iron deficiency and anemia in inflammatory bowel diseases. Inflamm Bowel. 2007;13(12):1545-1553.

3. Jahn MR, Andreasen HB, Fütterer S, et al. A comparative study of the physicochemical properties of iron isomaltoside $1000\left(\right.$ Monofer $\left.^{\text {( }}\right)$, a new intravenous iron preparation and its clinical implications. Eur J Pharm Biopharm. 2011;78(3):480-491.

4. Medical Dictionary for Regulatory Activities. Maintenance and Support Services Organization, 2010. Available from: http://www.meddramsso. com/. Accessed on January 11, 2012.

5. Lennard-Jones JE, Shivananda S; EC-IBD Study Group. Clinical uniformity of inflammatory bowel disease at presentation and during the first year of disease in the north and south of Europe. Eur J Gastroenterol Hepatol. 1997;9(4):353-359.

6. Seligman PA, Dahl NV, Strobos J, et al. Single-dose pharmacokinetics of sodium ferric gluconate complex in iron-deficient subjects. Pharmacotherapy. 2004;24(5):574-583.

7. Warady BA, Seligman PS, Dahl NV. Single-dosage pharmacokinetics of sodium ferric gluconate complex in iron-deficient pediatric hemodialysis patients. Clin J Am Soc Nephrol. 2007;2(6):1140-1146.

8. Landry R, Jacobs PM, Davis R, Shenouda M, Bolton WK. Pharmacokinetic study of ferumoxytol: a new iron replacement therapy in normal subjects and hemodialysis patients. Am J Nephrol. 2005;25(4):400-410.

9. Pai AB, Nielsen JC, Kausz A, Miller P, Owen JS. Plasma pharmacokinetics of two consecutive doses of ferumoxytol in healthy subjects. Clin Pharmacol Ther. 2010;88(2):237-242. 
10. Fütterer S, Andreasen H, Jahn M, Nawroth T, Langguth P. Comparison of nanoparticular iron formulations for parenteral use - are they similar and readily exchangeable? Poster presented at Jahrestagung 2010 der Deutschen Pharmazeutischen Gesellschaft; October 4-7, 2010.

11. Henderson PA, Hillman RS. Characteristics of iron dextran utilization in man. Blood. 1969;34(3):357-375.

12. Danielson BG, Salmonson T, Derendorf H, Geisser P. Pharmacokinetics of iron(III)-hydroxide sucrose complex after a single intravenous dose in healthy volunteers. Arzneimittelforschung. 1996;46(6):615-621.

13. Danielson BG. Structure, chemistry, and pharmacokinetics of intravenous iron agents. J Am Soc Nephrol. 2004;15(Suppl 2):S93-S98.

14. Ferinject, summary of product characteristics, the electronic Medicines Compendium (eMC), updated August 11, 2009. Available from: http:// www.medicines.org.uk/EMC/medicine/24167/SPC/Ferinject+(ferric+ carboxymaltose)/. Accessed January 11, 2012.
15. Australian Public Assessment Report for Ferric Carboxymaltose. TGA May 2011. Available from: http://www.tga.gov.au/pdf/auspar/ausparferric.pdf. Accessed January 11, 2012.

16. Wikström B, Bhandari S, Barany P, et al. Iron isomaltoside 1000: a new intravenous iron for treating iron deficiency in chronic kidney disease. J Nephrol. 2011;24(5):589-596.

17. Hildebrandt PR, Bruun NE, Nielsen OW, et al. Effects of administration of iron isomaltoside 1000 in patients with chronic heart failure. A pilot study. Transfus Altern Transfus Med. 2010;11(4):131-137.

\section{Publish your work in this journal}

Drug Design, Development and Therapy is an international, peerreviewed open-access journal that spans the spectrum of drug design and development through to clinical applications. Clinical outcomes, patient safety, and programs for the development and effective, safe, and sustained use of medicines are a feature of the journal, which has also been accepted for indexing on PubMed Central. The manuscript management system is completely online and includes a very quick and fair peer-review system, which is all easy to use. Visit http://www.dovepress.com/testimonials.php to read real quotes from published authors.

Submit your manuscript here: http://www.dovepress.com/drug-design-development-and-therapy-journal 